12 Sperling MR, Feldman $\mathrm{H}$, Kinman J, et al. Seizure control and mortality in epilepsy. Ann Neurol 1999;46:45-50.

13 Brorson LO, Wranne L. Long-term prognosis in childhood epilepsy: survival and seizure prognosis. Epilepsia 1987;28:324-30.

14 Harvey AS, Nolan T, Carlin JB. Community-based study of mortality in children with epilepsy. Epilepsia 1993;34:597-603.

15 Appleton RE. Sudden, unexpected death in epilepsy in children. Seizure 1997;6:175-7.

16 Sillanpaa $M$, Jalava $M$, Kaleva $O$, et al. Long-term prognosis of seizures with onset in childhood. N Engl J Med 1998;338:1715-22.

17 Callenbach PMC, Westendorp RGJ, Geerts AT, et al. Mortality risk in children with epilepsy: the Dutch study of epilepsy in childhood. Pediatrics 2001;107:1259-63.
18 Camfield CS, Camfield PR, Veugelers PJ. Death in children with epilepsy: a population-based study. Lancet 2002;359:1891-5.

19 Appleton RE, Cross H. A National UK Audit into epilepsy-related deaths [letter]. Dev Med Child Neurol 1999:41:789.

20 Preston J. Information on sudden deaths from epilepsy. Epilepsia 1997;38(suppl 11):S72-4.

21 Green S. Risk and advice in child neurology. Dev Med Child Neurol 2000;42:795.

22 Fish DR. Sudden unexpected death in epilepsy: impact on clinical practice. Epilepsia 1997:38(suppl. 11):S60-2.

23 Bax MCO. Disclosure. Dev Med Child Neurol 2002;44:579.

24 Calman KC. Cancer, science and society and the communication of risk. BMJ 1996:313:799-802.

\title{
ARCHIVIST
}

\section{Pimecrolimus cream for atopic dermatitis}

t least half of young children who develop atopic dermatitis $(\mathrm{AD})$ do so within the

first 6 months of life and there is evidence that early treatment might affect prognosis. Topical corticosteroid preparations are often used but the possible adverse effects are well known. Pimecrolimus, an inhibitor of proinflammatory cytokines, has been used successfully, apparently with minimal systemic absorption after topical application. Now a larger, multicentre trial (Vincent C Ho and colleagues. Journal of Pediatrics 2003;142:155-62) has confirmed the benefit.

A total of 186 children aged 3-23 months with mild or moderate AD were randomised (2:1) at 25 centres in six countries to pimecrolimus $1 \%$ cream or placebo twice daily for six weeks. After that all patients were given open label pimecrolimus for 20 weeks. At the end of the first six weeks $55 \%$ (pimecrolimus) versus $24 \%$ (placebo) were rated clear or almost clear of AD. By day 8 pruritus was considered absent or mild in $70 \%$ versus $37 \%$ and by day 43 in $72 \%$ versus 33\%. Patients transferred to pimecrolimus in the open label phase did equally well and benefit was maintained throughout this phase. Adverse events were usually mild and not thought to be related to treatment.

Pimecrolimus $1 \%$ seems to be effective and safe treatment for young children with AD. 